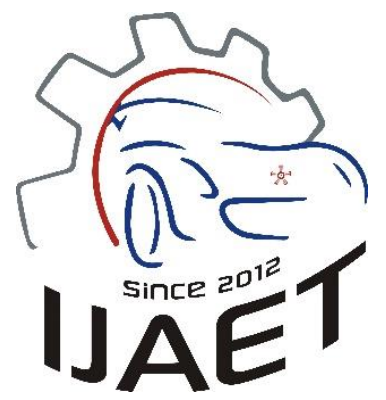

e-ISSN: 2146 - 9067

International Journal of Automotive

Engineering and Technologies

journal homepage: http://ijaet.academicpaper.org

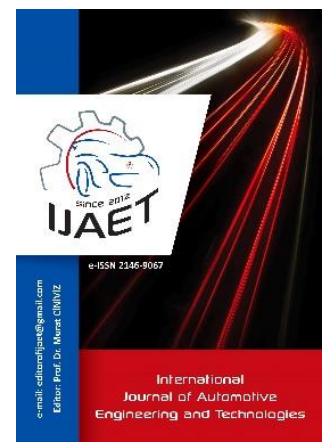

Original Research Article

\title{
The determination of the effect of mixture proportions and production parameters on density and porosity features of Miscanthus reinforced brake pads by Taguchi method
}

\author{
Mahmut Ünald1 ${ }^{1 *}$, Recai Kuş ${ }^{2}$ \\ 1 Selçuk University, Cihanbeyli Vocational School, Department of Motor Vehicles and Transportation Technologies, \\ Konya/Turkey \\ ${ }^{2}$ Selcuk University, Faculty of Technology, Department of Mechanical Engineering, Konya/Turkey
}

\section{ARTICLE INFO}

* Corresponding author munaldi@selcuk.edu.tr

Received: November 05, 2017

Accepted: March 15, 2018

Published by Editorial Board Members of IJAET

(C) This article is distributed by Turk Journal Park System under the CC 4.0 terms and conditions.

\begin{abstract}
Brake pads are generally consisted of five different component groups. These groups are named as reinforcements, binders, abrasives, lubricants and fillers. Each of these groups has its own function such as to improve friction property, wear resistance, to increase strength, and to reduce porosity and noise. In this study, Miscanthus as reinforcement, cashew as lubricant, alumina as abrasive, calcite as filler, and phenolic resin as binder were used to produce composite ecological brake pad samples. Brake pads are usually developed through trial and error method and therefore, the evaluation process became complicated and time consuming due to the multiplicity of components, randomly selected mixing ratios, results obtained from the experiments, etc. and so Taguchi method is utilized to get rid of these difficulties of trial and error method. This study was made in order to determine the influence level of the brake pad ingredients and some production parameters to the density and porosity features of the brake pad samples. The ecological brake pad samples were manufactured and experiments were conducted to Taguchi Method $\mathrm{L}_{32}$ orthogonal array. According to the ANOVA (Analysis of Variance) tables and other graphical results obtained from Taguchi method, the density feature of brake pad samples is more affected by the mixture proportion factors and moulding temperature, curing time and curing temperature factors have a minor effect on porosity feature of brake pad samples.
\end{abstract}

Keywords: ANOVA, Brake pad, Density, Miscanthus, Porosity, Taguchi method

\section{Introduction}

Brake pads that are consisted of components such as reinforcements, binders, abrasives, lubricants and fillers can be classified as metallic, mineral, ceramic, or organic. Reinforcements, fillers, abrasives, lubricants and binders used for to strengthen the composite structure, to keep the composite structure in monolithic state, to improve the wear resistance of brake pads, to maintain stable coefficient of friction, and to reduce costs, etc. Each component has its own function such as to improve friction property, wear resistance, increase strength, reduce porosity and noise and so, changes in component types and weight percentages of the components in the formulation change all properties of the brake pad that is manufactured [1-3].

The brake pads should have stable coefficient of friction under different operating conditions, high wear resistance, low cost, high heat capacity, good thermal conductivity, should be 
safe to use and acceptable for the environment, and does not damage the brake disc etc. It is impossible to obtain any desired properties from brake pads because they consist of many ingredients and in different mixture proportions [4-6].

Miscanthus plant is cultivated in order to purify the sewage treatment and to dry the marshes. The rapid growth, low mineral content, and high biomass yield of Miscanthus makes it advantageous for use as chipboard, automobile part (such as interior parts, seat, plastic parts etc.), insulation material, building material, solid-liquid-gaseous fuel. In the study conducted by Acikel [7], Miscanthus plant which was grinded and chopped was used as reinforcing component in concrete and compression, splitting and bending tests were performed on the produced specimens. Miscanthus component used as a concrete admixture has increased the compression, tension and bending strength of concrete.

Composite materials as brake pads are usually developed through trial and error method, coupled with prior experience of researchers. The experimental data evaluation process has become complicated and time consuming because of randomly selected mixing ratio of components, the number of components used for brake pad manufacturing, the number of samples that can be produced by trial-and-error method and the multiplicity of experimental data. Taguchi method is utilized to get rid of these difficulties of trial and error method. In recent days, the effect of the brake pad components' compositions, production parameters, brake system components etc. on the physical, chemical and tribological properties of the brake pad samples or various operating parameters of brake system have been researched through the Taguchi method by the many researchers.

The best production parameters for wear resistance and friction stability of brake pads containing 15 ingredients were determined via Taguchi method in the study conducted by Kim, Kim and Jang [8]. The researchers noted that there is no relationship between the physical and tribological properties of brake pad samples.

Singh, Kumar and Kumar [9] did a study to minimize the failure of disc brake according to back plate thickness, slots width and slots angle by using Taguchi method. As a result of experiments conducted to orthogonal array layout of $\mathrm{L}_{8}$, the optimum slot width of $3 \mathrm{~mm}$ obtained.

Ficici, Durat and Kapsiz [10] investigated to analyses the effects of the operating parameters and interactions on the wear properties of brake pad using Taguchi method. It was expressed that the weight loss affected by volume fraction, the pressure, and sliding distance in descending order. The optimal parameters found as the highest level of volume fraction and the lowest level of pressure, sliding distance and sliding speed.

Maleque and Atiqah [11] found that the porosity of the material decreases with increase in the density value and the sample which has higher hardness value of 63.92 HRS and lower porosity value was obtained with $5 \%$ coir.

Porosity in automotive brake pad materials has a crucial role because of absorbs energy and heat and affects the brake system effectiveness. Theoretically, friction coefficient and wear rate values of samples with low porosity have higher values because low porosity means increased contact areas between mating surfaces. Some researchers declared that brake pads should have a certain amount of porosity to reduce the brake noise as a result of their findings, friction materials with low hardness show higher porosity and lower density and they should have up to $12 \%$ of porosity value in order to maintain sufficient strength and high porosity tends to be exhibit high friction coefficient [12-15].

In braking applications, heat is generated due to friction during braking and friction coefficient decreases because of the increasing interface temperature. Therefore, the decrease in friction coefficient should be low value for an effective braking [16]. Boz and Kurt [16] reported that coefficient of friction decreased with the increasing porosity values due to the temperature effect in bronze based powder metallurgy friction materials. Ostermeyer [17] also reported that friction coefficient decreases with increase in interface temperature.

Mutlu, Sugözü and Keskin [18] made a research about the effect of porosity on the friction and wear properties of brake pads. The porosity values of brake pads produced for the 
study ranged from 6-18\%. According to the data obtained from experiments, the porosity values were inversely proportional to the density values of the samples.

Earlier researchers [1, 19] have concluded that there is no simple correlation between the physical and mechanical properties of friction materials. Therefore, new brake pad formulations developed needs to be subjected to a series of tests to evaluate the properties.

In this study, Miscanthus, Cashew, Alumina, Phenolic Resin, Moulding temperature value, Moulding Pressure value, Curing time, Curing temperature value were selected as factors and mixed-level designs of the Taguchi method were used because of the number of factors and their levels. So, thirty-two eco-friendly brake samples were produced according to Taguchi Method $\mathrm{L}_{32}$ orthogonal array based on the changes made in the producing and mixture proportion parameters. Taguchi optimization method is used for to determine the levels of producing and mixture proportion parameters affecting the density and porosity features of brake pad samples, and to identify the degree of influence of each factors selected by the researchers to the density and porosity features.
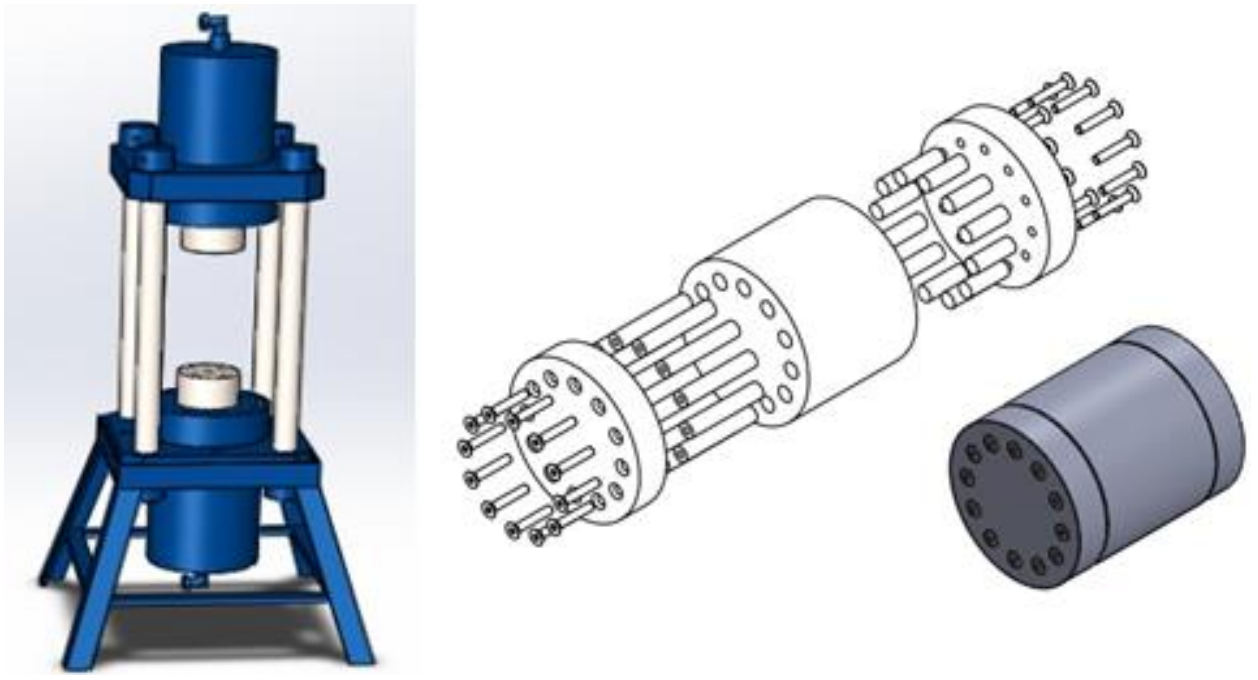

Figure 1. The double acting hydraulic press and the mould

Table 1. The Factors and their levels for Taguchi method

\section{Levels}

\begin{tabular}{lccccc}
\multicolumn{1}{c}{ Factors } & Symbol & $\mathbf{1}$ & $\mathbf{2}$ & $\mathbf{3}$ & $\mathbf{4}$ \\
\hline Moulding Temp. $\left({ }^{\circ} \mathrm{C}\right)$ & $\mathrm{T} 1$ & 160 & 170 & - & - \\
Miscanthus $(\%)$ & Msc & 5 & 10 & 15 & 20 \\
Cashew $(\%)$ & Csh & 10 & 15 & 20 & 25 \\
Alumina (\%) & Alu & 10 & 15 & 20 & 25 \\
Phenolic Resin $(\%)$ & PR & 10 & 15 & 20 & 25 \\
Moulding Prs. $(\mathrm{MPa})$ & Prs & 100 & 125 & 150 & 175 \\
Curing Time $(\mathrm{h})$ & $\mathrm{tm}$ & 1 & 2 & 4 & 6 \\
Curing Temp. $\left({ }^{\circ} \mathrm{C}\right)$ & $\mathrm{T} 2$ & 150 & 160 & 170 & 180 \\
\hline
\end{tabular}

\section{Materials and Method}

The powder materials to produce used for brake pad samples in this study were chosen as Miscanthus (reinforcement), Cashew (lubricant), Alumina (abrasive), Phenolic Resin (binder), and Calcite (filler). The characteristics and production conditions of Miscanthus cane plant used in this study are specified in the study conducted by Geren, Kavut and Avcioğlu [20]. The Miscanthus component used as reinforcement was used for the first time as a fiber in friction materials. The mixture proportions of Miscanthus (Msc) were chosen in the range of 5-20 wt-\%, due to its low bulk density. Because of the ineffective components 
in the mixture as reported in the literature, Calcite used as filler (in the range of 35-80 wt$\%$ ) in composite brake pad material was preferred as a complement ingredient. The mixture proportions of other brake pad ingredients such as Cashew (Csh), alumina (Alu) and phenolic resin (PR) used for production of ecological brake pad samples were chosen in the range of $10-25 \mathrm{wt}-\%$ increased by $5 \mathrm{wt}-\%$. The mixture proportions values of ingredients used for manufacturing brake pad samples are denoted in Table-1. Brake pad samples which are dimensioned as diameter $12 \mathrm{~mm}$, height $25 \mathrm{~mm}$ were produced in the mould (Fig.1) with a double acting hydraulic press machine.

The mixture proportion of brake pad ingredients are adjusted using $1 \mathrm{mg}$ precision scale and ingredients are blended with a 1000 $\mathrm{W}$ electric mixer, and then moulded with a double acting hydraulic press machine. The manufactured brake pad samples are polished by sand paper with the size of 320, 400, 600 and 800 grit in order to prepare the samples for experiments.

Many natural and manufactured materials which are used for manufacturing of brake pads consist of differently shaped and sized particles. Sieve analysis is the oldest and bestknown method for determination of particle size distribution that is defined via the mass or volume. The particle size distribution determined by sieve analysis affects the properties such as compressibility, conductivity, mechanical bulk behaviour, filtration properties, surface reaction, miscibility, etc. Sieve analysis is used to divide the particulate material into size fractions and then to determine the weight of these fractions. Sieve analyses (ASTM E11) are performed with sieve shaker via 15 min shaking time and 5 sets of sieve sizes; $500 \mu \mathrm{m}, 250 \mu \mathrm{m}, 125 \mu \mathrm{m}$, $63 \mu \mathrm{m}, 45 \mu \mathrm{m}$, and pan. The masses of the fractions retained on each sieves weighed on a precision scale and expressed as percentages of the ingredient powder mass [21].

The apparent (bulk) density of the powdered and granular materials which depends on the form of the particles can be calculated by the ratio of the mass to a given volume. It calculated by measuring the mass of a known volume of powder that has been passed through into a cup named Scott Volumeter which is used for determining the apparent density (ASTM B329). Apparent density depends on particle shape, particle size and particle distribution of the powder materials and used to obtain information about the porosity of the powdered materials and fluency of powdered materials into the mould in compaction process.

The density values $(d)$ of brake pad samples are determined through the Archimedean principle in accordance with ASTM B962-13. A digital precision scale which has density measurement kit was used for determination the density values. Density values possessed by the brake pad sample depend on physical features of ingredients and their mixing ratios. Organic ingredients have lower density values than metallic.

Porosity is a measure of the void fraction in a material. The voids can either be "closed" located inside of the material and inaccessible or 'open' located on the material surface. The porosity, which is the percentage of pore volume with the bulk total volume of the specimens', is deduced from the density value. Porosity (Pr), affects strength, thermal conductivity, noise insulation and water absorption properties of composite brake pad materials. The porosity values of the samples were determined by equation-1: $[14,15,18,22$, 23]

$\operatorname{Pr}=\left(1-\frac{\rho_{\mathrm{E}}}{\rho_{\mathrm{T}}}\right) \times 100$

where $\operatorname{Pr}$ is porosity $(\%), \rho_{\mathrm{E}}$ is experimental density $\left(\mathrm{g} / \mathrm{cm}^{3}\right)$ and $\rho_{\mathrm{T}}$ is theoretical density $\left(\mathrm{g} / \mathrm{cm}^{3}\right)$. The theoretical densities of samples were calculated by considering the theoretical densities of ingredients using law of mixture [24].

Brake pad samples in vast numbers can be manufactured considering the mixing ratios determined by the researchers. But it is impossible because of the performing production, experimentation and evaluation processes of the brake pad samples. For these reasons, design of experiment is an important tool for designing processes and products. The Taguchi method tests pairs of combinations of selected parameters instead of testing all possible combinations like the factorial design. 
Signal-to-Noise ratios $(\mathrm{S} / \mathrm{N})$ are used as the quality characteristics of choice on Taguchi Design. The term 'signal' represents the desirable target for good products and the term 'noise' expresses the undesirable value. The experimental observations are transformed into signal-to-noise $(\mathrm{SN})$ ratios and the goal of the experiment is to improve the relationship between the signal factor and the response. The signal-to-noise ratio measures how the response varies under different noise conditions. SN ratios are available depending on the type of performance characteristics and can be characterized into three categories; Larger is better, Nominal is the best and Smaller is better. The SN ratio category selected is important for the goal of the experiments. The parameter level which has the highest $\mathrm{S} / \mathrm{N}$ value is the best result for the experiments regardless of the selected category of performance characteristics. Herewith, the optimal level of the parameters is the highest level of the $\mathrm{S} / \mathrm{N}$ value in the $\mathrm{S} / \mathrm{N}$ tables [25, 26]. $P$ values are used to determine statistical significance in statistics. The factors whose $\mathrm{P}$ values are less than $0.05 \%$ are regarded as statistically significant $[10,27]$.

In this work, to evaluate the statistical data, the larger-is-better quality characteristic (equation2) was chosen for density and the smaller-isbetter quality characteristic (equation-3) was chosen for porosity feature of brake pad samples. The quality characteristic was chosen in accordance with the previously conducted studies made by Ibhadode and Dagwa [28]; Kim et al. [8]; Zaharudin et. al. [29]. These formulas were used to calculate $\mathrm{SN}$ ratio:

Larger is better $\mathrm{S} / \mathrm{N}=-10 \cdot \log \left[\Sigma\left(1 / \mathrm{Y}^{2}\right) / \mathrm{n}\right]$

Smaller is better $\mathrm{S} / \mathrm{N}=-10 \cdot \log \left(\Sigma \mathrm{Y}^{2} / \mathrm{n}\right)$

$\mathrm{Y}=$ measured value, $\mathrm{n}=$ Number of tests.

\section{Results and Discussion}

The graph of sieve analysis results of all brake pad ingredients is given in Fig.2. Miscanthus and Cashew powdered components have bigger granular structure than the others according to the sieve analysis. Phenolic resin component has more balanced grain size distribution because a certain amount of powder accumulated on each sieve. Alumina has the finest grain structure. The results of sieve analysis are important because it affects density and porosity features of brake pads.

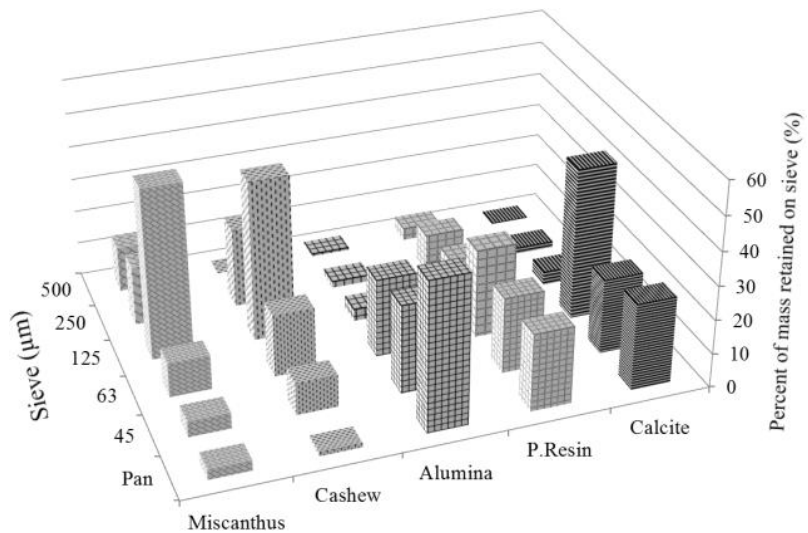

Figure 2. Sieve analysis results of all brake pad ingredients

The ratios of the components in the mixture and the production parameters are specified for each brake pad samples to be produced separately in Table 2. The all experiments are conducted in accordance with Taguchi's $\mathrm{L}_{32}$ orthogonal array. The numbers in each column at Table-2 indicates the levels for the factors mentioned in Table 1 and due to $\mathrm{L}_{32}$ orthogonal array, 32 brake pad samples which has different parameter should be manufacture for experiments to examine the all parameters. The experiments were carried out three times and average values of the experiments data and the $\mathrm{S} / \mathrm{N}$ values are given in Table 3 . Density and porosity values of brake pad samples are changed in the following range 1.42-1.87 $\left(\mathrm{g} / \mathrm{cm}^{3}\right)$ and 7.2-25.3 (\%), respectively. Any comments can be made about density and porosity values of brake pad samples in Table 3 due to the mixture ratios and production parameters are different for all samples.

Analysis of Variance (ANOVA) and response tables obtained by applying the result of experiments to the Taguchi method are given in Table 4-7. The descriptions of symbols which are located in tables and graphs are given in Table 1.

The ANOVA tables in Table 4 and 5 show the relative importance of the selected parameters affecting the density and porosity of brake pad samples. The relative importance of the selected parameters can be evaluated with the percentage contribution (Cont.\%) located in the tables. The percentage contribution (Cont.\%) is 
calculated from the total sum of squared deviation of $\mathrm{S} / \mathrm{N}$ ratio and indicates their degree of influence on the result. In the analysis, the F-ratio is used to indicate the significance of any factor. The F-value expresses which parameter has an important influence over the process response. The Pvalue in ANOVA tables is an indicator to demonstrate the significance level (suitable or unsuitable) for the density and porosity.

Table 2. $\mathrm{L}_{32}$ orthogonal array according to Taguchi's suggestion

\begin{tabular}{cccccccccccccccccc}
\hline No & T1 & Msc & Csh & Alu & PR & Prs & tm & T2 & No & T1 & Msc & Csh & Alu & PR & Prs & tm & T2 \\
\hline $\mathbf{1}$ & 1 & 1 & 1 & 1 & 1 & 1 & 1 & 1 & $\mathbf{1 7}$ & 2 & 1 & 1 & 4 & 1 & 4 & 2 & 3 \\
$\mathbf{2}$ & 1 & 1 & 2 & 2 & 2 & 2 & 2 & 2 & $\mathbf{1 8}$ & 2 & 1 & 2 & 3 & 2 & 3 & 1 & 4 \\
$\mathbf{3}$ & 1 & 1 & 3 & 3 & 3 & 3 & 3 & 3 & $\mathbf{1 9}$ & 2 & 1 & 3 & 2 & 3 & 2 & 4 & 1 \\
$\mathbf{4}$ & 1 & 1 & 4 & 4 & 4 & 4 & 4 & 4 & $\mathbf{2 0}$ & 2 & 1 & 4 & 1 & 4 & 1 & 3 & 2 \\
$\mathbf{5}$ & 1 & 2 & 1 & 1 & 2 & 2 & 3 & 3 & $\mathbf{2 1}$ & 2 & 2 & 1 & 4 & 2 & 3 & 4 & 1 \\
$\mathbf{6}$ & 1 & 2 & 2 & 2 & 1 & 1 & 4 & 4 & $\mathbf{2 2}$ & 2 & 2 & 2 & 3 & 1 & 4 & 3 & 2 \\
$\mathbf{7}$ & 1 & 2 & 3 & 3 & 4 & 4 & 1 & 1 & $\mathbf{2 3}$ & 2 & 2 & 3 & 2 & 4 & 1 & 2 & 3 \\
$\mathbf{8}$ & 1 & 2 & 4 & 4 & 3 & 3 & 2 & 2 & $\mathbf{2 4}$ & 2 & 2 & 4 & 1 & 3 & 2 & 1 & 4 \\
$\mathbf{9}$ & 1 & 3 & 1 & 2 & 3 & 4 & 1 & 2 & $\mathbf{2 5}$ & 2 & 3 & 1 & 3 & 3 & 1 & 2 & 4 \\
$\mathbf{1 0}$ & 1 & 3 & 2 & 1 & 4 & 3 & 2 & 1 & $\mathbf{2 6}$ & 2 & 3 & 2 & 4 & 4 & 2 & 1 & 3 \\
$\mathbf{1 1}$ & 1 & 3 & 3 & 4 & 1 & 2 & 3 & 4 & $\mathbf{2 7}$ & 2 & 3 & 3 & 1 & 1 & 3 & 4 & 2 \\
$\mathbf{1 2}$ & 1 & 3 & 4 & 3 & 2 & 1 & 4 & 3 & $\mathbf{2 8}$ & 2 & 3 & 4 & 2 & 2 & 4 & 3 & 1 \\
$\mathbf{1 3}$ & 1 & 4 & 1 & 2 & 4 & 3 & 3 & 4 & $\mathbf{2 9}$ & 2 & 4 & 1 & 3 & 4 & 2 & 4 & 2 \\
$\mathbf{1 4}$ & 1 & 4 & 2 & 1 & 3 & 4 & 4 & 3 & $\mathbf{3 0}$ & 2 & 4 & 2 & 4 & 3 & 1 & 3 & 1 \\
$\mathbf{1 5}$ & 1 & 4 & 3 & 4 & 2 & 1 & 1 & 2 & $\mathbf{3 1}$ & 2 & 4 & 3 & 1 & 2 & 4 & 2 & 4 \\
$\mathbf{1 6}$ & 1 & 4 & 4 & 3 & 1 & 2 & 2 & 1 & $\mathbf{3 2}$ & 2 & 4 & 4 & 2 & 1 & 3 & 1 & 3 \\
\hline
\end{tabular}

Table 3. Experimental results and $\mathrm{S} / \mathrm{N}$ ratios

\begin{tabular}{cccccccccc}
\hline No & $\mathbf{d}$ & $\mathbf{d} \_\mathbf{S} / \mathbf{N}$ & $\mathbf{P r}$ & $\mathbf{P r} \_\mathbf{S} / \mathbf{N}$ & No & $\mathbf{d}$ & $\mathbf{d} \_\mathbf{S} / \mathbf{N}$ & $\mathbf{P r}$ & $\mathbf{P r} \_\mathbf{S} / \mathbf{N}$ \\
\hline $\mathbf{1}$ & 1.770 & 4.961 & 24.97 & 12.05 & $\mathbf{1 7}$ & 1.874 & 5.455 & 25.32 & 11.93 \\
$\mathbf{2}$ & 1.758 & 4.899 & 21.72 & 13.26 & $\mathbf{1 8}$ & 1.748 & 4.849 & 23.87 & 12.44 \\
$\mathbf{3}$ & 1.681 & 4.511 & 21.14 & 13.50 & $\mathbf{1 9}$ & 1.687 & 4.542 & 18.95 & 14.45 \\
$\mathbf{4}$ & 1.743 & 4.826 & 13.61 & 17.32 & $\mathbf{2 0}$ & 1.671 & 4.459 & 10.52 & 19.55 \\
$\mathbf{5}$ & 1.684 & 4.528 & 22.93 & 12.79 & $\mathbf{2 1}$ & 1.812 & 5.163 & 22.41 & 12.99 \\
$\mathbf{6}$ & 1.645 & 4.321 & 25.06 & 12.02 & $\mathbf{2 2}$ & 1.682 & 4.515 & 25.08 & 12.01 \\
$\mathbf{7}$ & 1.759 & 4.905 & 10.14 & 19.88 & $\mathbf{2 3}$ & 1.692 & 4.568 & 11.3 & 18.93 \\
$\mathbf{8}$ & 1.686 & 4.538 & 14.25 & 16.92 & $\mathbf{2 4}$ & 1.599 & 4.078 & 11.96 & 18.44 \\
$\mathbf{9}$ & 1.784 & 5.026 & 13.48 & 17.40 & $\mathbf{2 5}$ & 1.703 & 4.625 & 19.33 & 14.27 \\
$\mathbf{1 0}$ & 1.614 & 4.158 & 12.64 & 17.96 & $\mathbf{2 6}$ & 1.777 & 4.993 & 11.04 & 19.13 \\
$\mathbf{1 1}$ & 1.586 & 4.004 & 23.75 & 12.49 & $\mathbf{2 7}$ & 1.512 & 3.592 & 21.62 & 13.30 \\
$\mathbf{1 2}$ & 1.573 & 3.936 & 15.66 & 16.10 & $\mathbf{2 8}$ & 1.639 & 4.292 & 9.7 & 20.22 \\
$\mathbf{1 3}$ & 1.716 & 4.688 & 9.1 & 20.81 & $\mathbf{2 9}$ & 1.720 & 4.710 & 11.23 & 18.98 \\
$\mathbf{1 4}$ & 1.667 & 4.439 & 7.19 & 22.80 & $\mathbf{3 0}$ & 1.657 & 4.387 & 14.86 & 16.55 \\
$\mathbf{1 5}$ & 1.604 & 4.106 & 15.81 & 16.02 & $\mathbf{3 1}$ & 1.551 & 3.812 & 11.65 & 18.67 \\
$\mathbf{1 6}$ & 1.511 & 3.583 & 16.74 & 15.52 & $\mathbf{3 2}$ & 1.419 & 3.041 & 19.56 & 14.17 \\
\hline
\end{tabular}

Miscanthus, Cashew, Alumina, and Phenolic Resin have statistically significant effect on density feature of brake pad samples because these factors' $P$ values are lower than 0.05 in Table 4. Cashew and Miscanthus factors are more effective components because their
Contribution values are 37.45 and 28.63, and F-values are 21.05 and 16.09, respectively.

As seen in Table 5, only Miscanthus and Phenolic Resin are statistically significant for porosity feature of brake pad samples. These factors are more influential than the other 
factors due to $\mathrm{F}$ and Contribution (\%) values of Miscanthus and Phenolic Resin are 6.25-18.5\% and $17.79-52.7 \%$, respectively. Especially the factors as moulding temperature, curing time and curing temperature have no significant impact on porosity. R-Sq values of SN Ratios of density and porosity of manufactured brake pad samples are 94.7, and 91.1, respectively.

Table 4. ANOVA Results of Density

\begin{tabular}{lcccccc}
\hline & DF & Seq SS & Adj MS & F & P & Cont. (\%) \\
\hline T1 & 1 & 0.0038 & 0.0038 & 0.08 & 0.783 & 0.05 \\
Msc & 3 & 2.3030 & 0.7676 & 16.09 & 0.001 & 28.63 \\
Csh & 3 & 3.0125 & 1.0041 & 21.05 & 0.000 & 37.45 \\
Alu & 3 & 0.7530 & 0.251 & 5.26 & 0.023 & 9.36 \\
PR & 3 & 0.9671 & 0.3223 & 6.76 & 0.011 & 12.02 \\
Prs & 3 & 0.5041 & 0.168 & 3.52 & 0.062 & 6.27 \\
tm & 3 & 0.0223 & 0.0074 & 0.16 & 0.923 & 0.28 \\
T2 & 3 & 0.0478 & 0.0159 & 0.33 & 0.801 & 0.59 \\
Err. & 9 & 0.4292 & 0.0477 & & & \\
Total & 31 & 8.0432 & & & & \\
\hline
\end{tabular}

Table 5. ANOVA Results of Porosity

\begin{tabular}{lcccccc}
\hline & DF & Seq SS & Adj MS & F & P & Cont. (\%) \\
\hline T1 & 1 & 0.0210 & 0.021 & 0.01 & 0.935 & 0.01 \\
Msc & 3 & 55.945 & 18.648 & 6.25 & 0.014 & 18.51 \\
Csh & 3 & 19.326 & 6.442 & 2.16 & 0.163 & 6.39 \\
Alu & 3 & 14.668 & 4.889 & 1.64 & 0.249 & 4.85 \\
PR & 3 & 159.28 & 53.095 & 17.79 & 0.000 & 52.7 \\
Prs & 3 & 24.946 & 8.315 & 2.79 & 0.102 & 8.25 \\
tm & 3 & 0.3070 & 0.102 & 0.03 & 0.991 & 0.1 \\
T2 & 3 & 0.8630 & 0.288 & 0.1 & 0.96 & 0.29 \\
Err. & 9 & 26.866 & 2.985 & & & \\
Total & 31 & 302.225 & & & & \\
\hline
\end{tabular}

Table 6. Response Table for SN Ratios of Density

\begin{tabular}{ccccccccc}
\hline Level & T1 & Msc & Csh & Alu & PR & Prs & tm & T2 \\
\hline $\mathbf{1}$ & 4.464 & 4.813 & 4.895 & 4.253 & 4.184 & 4.420 & 4.495 & 4.499 \\
$\mathbf{2}$ & 4.443 & 4.577 & 4.570 & 4.422 & 4.448 & 4.417 & 4.455 & 4.481 \\
$\mathbf{3}$ & & 4.328 & 4.255 & 4.454 & 4.518 & 4.318 & 4.423 & 4.434 \\
$\mathbf{4}$ & & 4.096 & 4.094 & 4.684 & 4.663 & 4.659 & 4.441 & 4.400 \\
Delta & 0.022 & 0.717 & 0.800 & 0.431 & 0.479 & 0.341 & 0.072 & 0.098 \\
Rank & 8 & 2 & 1 & 4 & 3 & 5 & 7 & 6 \\
\hline
\end{tabular}

The calculated SN ratio values of density and delta value means that there is high correlation porosity values for selected factors and their levels are shown in Table 6-7 and Fig.3. Delta values in the response tables compare the relative magnitude of effects. Rank gives the sort of the delta values in descending order. Delta values in the Table 6 and 7, are equal the difference between the highest and the lowest value on each factors' level value. The highest between the characteristic and factors analysed. Table 6 shows the changes of SN ratios values calculated from the density values of brake pad samples. The most effective factors according to the order specified in Table 6 are Cashew, Miscanthus, Phenolic Resin and Alumina for density feature of brake pad samples. The S/N values of porosity feature of brake pad samples are shown in Table 7 . In particular, porosity 
feature is strongly affected by Phenolic Resin

and Miscanthus components.

Table 7. Response Table for SN Ratios of Porosity

\begin{tabular}{ccccccccc}
\hline Level & T1 & Msc & Csh & Alu & PR & Prs & tm & T2 \\
\hline $\mathbf{1}$ & 16.05 & 14.31 & 15.15 & 16.95 & 12.94 & 15.69 & 16.19 & 16.20 \\
$\mathbf{2}$ & 16.00 & 15.50 & 15.77 & 16.41 & 15.31 & 15.63 & 15.93 & 15.93 \\
$\mathbf{3}$ & & 16.36 & 15.90 & 15.34 & 16.79 & 15.26 & 15.99 & 16.17 \\
$\mathbf{4}$ & & 17.94 & 17.28 & 15.42 & 19.07 & 17.53 & 16.00 & 15.81 \\
Delta & 0.05 & 3.63 & 2.13 & 1.61 & 6.13 & 2.27 & 0.26 & 0.39 \\
Rank & 8 & 2 & 4 & 5 & 1 & 3 & 7 & 6 \\
\hline
\end{tabular}

Graphical representations of the data in Table 6 and 7, are given in Fig.3. The purpose of showing graphically the data in tables is easier to be understandable form. The value of the curve slope in the graphs indicates the strength

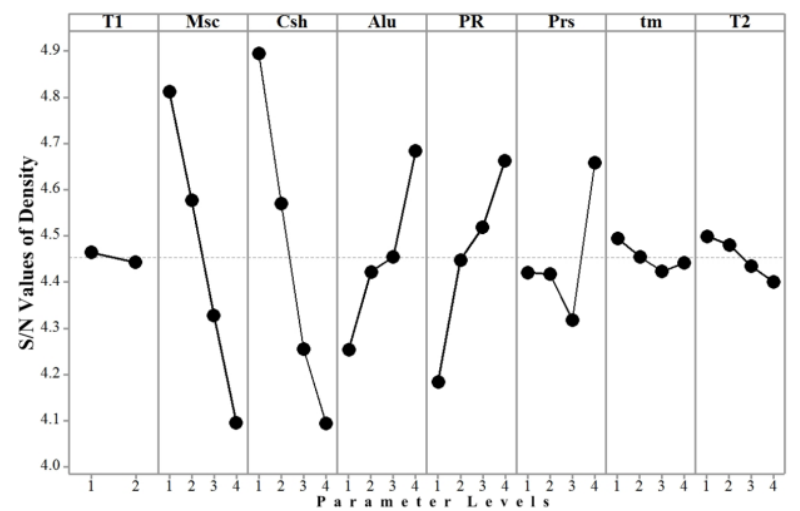

Figure 3. The main effects plot of $\mathrm{SN}$ ratios for density and porosity of the relation between the factor and response. The higher slope of the curve in the graphs means that there is a stronger relationship between the factor and the response.

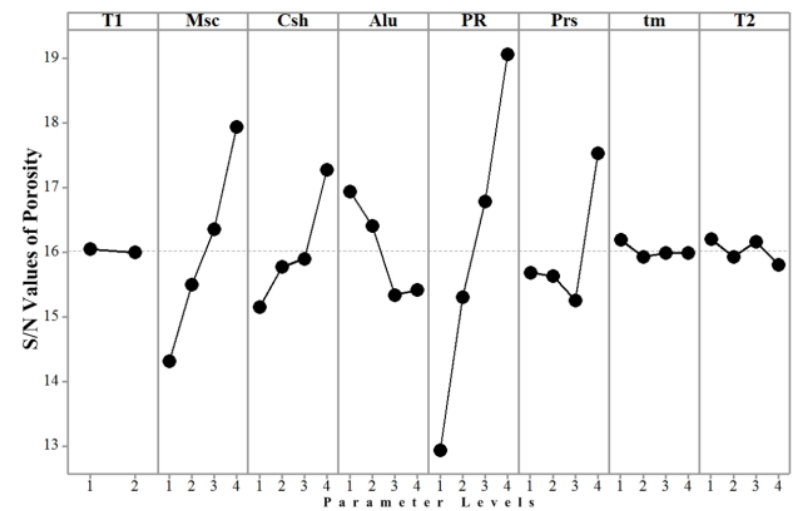

As seen in Fig. 3 at left side, Cashew and Miscanthus factors are more effective components for the density feature of brake pad samples because slopes of curves are higher than the other factors. Miscanthus and Phenolic Resin factors have more significant impact on porosity of brake pad samples. According to the graphs in Fig.3, Miscanthus ratio, Cashew ratio, moulding temperature, curing time and curing temperature should be the lowest level and the other factors should be the highest level for increasing the density values of brake pad samples in accordance with the components and the production parameters selected for this study. The moulding temperature, Alumina ratio, curing temperature and curing time should be the lowest level and other factors' values should be the highest level to decrease the porosity values of brake pad samples in Fig. 3 at right side.

\section{Conclusion}

In the literature, there are many studies investigating the parameters affecting the properties of the brake pads. In these studies, the parameters are examined in two groups as production and components separately and generally the trial-error method is preferred for determining the effect of changes in values of components, components ratios and production parameters to the characteristics and production parameters of the brake pads. But, this method is complicated, time consuming and costly due to number of components selected for the manufacturing brake pads, number of the samples produced, number of experiments to be performed on these samples, arrangement and interpretation of the experimental data etc. Various optimization methods can be utilized to get rid of these difficulties of trial and error method.

The Taguchi method was used in this study, to determine the mixing ratios of the components and the production parameters of constituting the brake pad samples affecting the density and porosity characteristics of the ecological brake pads. Taguchi method is an experimental optimization design method that can be applied straightforward and simply to many 
engineering situations. The Taguchi method allows for the analysis of many different parameters without a prohibitively high amount of experimentation. Since the Taguchi method allows for the analysis of many different parameters without very high amounts of experimentation, it was used to determine the effective factors and their effect levels on the density and porosity characteristics of the ecological brake pore samples produced in this study. Experiments are conducted in accordance with Taguchi's $\mathrm{L}_{32}$ orthogonal array because of the high number of the selected parameters. According to ANOVA and Response tables the following generalized conclusions can be drawn for this work:

The density feature of brake pad samples manufactured by selected components is more affected by the mixture proportion factors such as Miscanthus, cashew, alumina, and phenolic resin than the production parameters.

In order to have a maximum density value of the brake pad samples manufactured for this study, the values of Miscanthus ratio, cashew ratio, moulding temperature, curing time and curing temperature should be the lowest level and the other factors' values should be maximum. The optimum density value is determined as $2.38 \mathrm{~g} / \mathrm{cm}^{3}$ via Predict Taguchi Results.

The porosity feature of brake pad samples are more affected by phenolic resin and Miscanthus ratio than the others. The porosity feature is also more affected by the production parameters such as the density feature. Especially moulding temperature, curing time and curing temperature the factors have a minor effect on porosity feature.

The values of moulding temperature, alumina ratio, curing temperature and curing time should be the lowest level and other factors' values should be the highest level to decrease the porosity values of brake pad samples. The optimum porosity value is determined as $12.44 \%$ via Predict Taguchi Results.

\section{Acknowledgement}

The data in this paper were benefited from Ph.D. thesis studies of Mahmut ÜNALDI. The authors acknowledge the support provided by the Scientific Research Projects Coordinatorship of Selcuk University Contract
No: 13101024 . The authors would like to thank the Eren Balata AS for material supply.

\section{References}

[1] T.R. Jaafar, M.S. Selamat, R. Kasiran, Selection of Best Formulation for SemiMetallic Brake Friction Materials Development, in: K. Kondoh (Ed.) Powder Metallurgy2012, pp. 30.

[2] Y. Lu, A Combinatorial Approach for Automotive Friction Materials: Effects of Ingredients on Friction Performance, Composites Science and Technology, 66 (2006) 591-598.

[3] L. Ntziachristos, P. Boulter, Road vehicle tyre and brake wear, European Environment Agency EMEP/EEA Air Pollutant Emission İnventory Guidebook2009, European Environment Agency (EEA), Copenhagen, 2009.

[4] M.H. Cho, S.J. Kim, D. Kim, H. Jang, Effects of ingredients on tribological characteristics of a brake lining: an experimental case study, Wear, 258 (2005) 1682-1687.

[5] H. Jang, K. Ko, S.J. Kim, R.H. Basch, J.W. Fash, The Effect of Metal Fibers on The Friction Performance of Automotive Brake Friction Materials, Wear, 256 (2004) 406414.

[6] I. Mutlu, O. Eldogan, F. Findik, Tribological Properties of Some Phenolic Composites Suggested for Automotive Brakes, Tribology International, 39 (2006) 317-325.

[7] H. Acikel, The Use of Miscanthus (Giganteus) as A Plant Fiber in Concrete Production, Scientific Research and Essays, 6 (2011) 2660-2667.

[8] S.J. Kim, K.S. Kim, H. Jang, Optimization of manufacturing parameters for a brake lining using Taguchi method, Journal of Materials Processing Technology, 136 (2003) 202-208.

[9] K.H. Singh, A. Kumar, R. Kumar, Optimization of Quality and Performance of Brake Pads Using Taguchi's Approach, International Journal of Scientific \& Engineering Research, 5 (2014) 632-639.

[10] F. Ficici, M. Durat, M. Kapsiz, Optimization of tribological parameters for a brake pad using Taguchi design method, 
Journal of the Brazilian Society of Mechanical Sciences and Engineering, 36 (2014) 653-659.

[11] M. Maleque, A. Atiqah, Development and Characterization of Coir Fibre Reinforced Composite Brake Friction Materials, Arabian Journal for Science and Engineering, 38 (2013) 3191-3199.

[12] M. Eriksson, F. Bergman, S. Jacobson, On the nature of tribological contact in automotive brakes, Wear, 252 (2002) 2636.

[13] M. Eriksson, S. Jacobson, Tribological surfaces of organic brake pads, Tribology International, 33 (2000) 817-827.

[14] M. Maleque, A. Atiqah, R. Talib, H. Zahurin, New natural fibre reinforced aluminium composite for automotive brake pad, International Journal of Mechanical and Materials Engineering, 7 (2012).

[15] A. Sellami, M. Kchaou, R. Elleuch, A.-L. Cristol, Y. Desplanques, Study of the interaction between microstructure, mechanical and tribo-performance of a commercial brake lining material, Materials \& Design, 59 (2014) 84-93.

[16] A. Kurt, M. Boz, Wear Behaviour of Organic Asbestos Based and Bronze Based Powder Metal Brake Linings, Materials \& Design, 26 (2005) 717-721.

[17] G.P. Ostermeyer, On the dynamics of the friction coefficient, Wear, 254 (2003) 852858.

[18] Mutlu, I. Sugözü, A. Keskin, The effects of porosity in friction performance of brake pad using waste tire dust, Polímeros, 25 (2015) 440-446.

[19] R.J. Talib, A. Muchtar, C.H. Azhari, The Performance of Semi-Metallic Friction Materials For Passenger Cars, Jurnal Teknologi, 46 (2007) 53-72.

[20] H. Geren, Y.T. Kavut, R. Avcioğlu, A preliminary study on ensilability characteristics and yield and other related traits of elephant grass (Miscanthus× giganteus) under Mediterranean climatic conditions, Ege Üniversitesi Ziraat Fakültesi Dergisi, 48 (2011) 203-209.

[21] R.M. German, Powder Metallurgy and Particulate Materals Processing: The Processes, Materials, Products, Properties and Applications, Metal Powder Industries Federation2005.

[22] K. Alaneme, Influence of thermomechanical treatment on the tensile behaviour and CNT evaluated fracture toughness of borax premixed $\mathrm{SiCp}$ reinforced AA 6063 composites, International Journal of Mechanical and Materials Engineering, 7 (2012) 96-100.

[23] M. Lawrence, Y. Jiang, Porosity, Pore Size Distribution, Micro-structure, in: S. Amziane, F. Collet (Eds.) Bio-aggregates Based Building Materials : State-of-theArt Report of the RILEM Technical Committee 236-BBM, Springer Netherlands, Dordrecht, 2017, pp. 39-71.

[24] E.K. Girija, G.S. Kumar, A. Thamizhavel, Y. Yokogawa, S.N. Kalkura, Fabrication of Hydroxyapatite-Calcite Nanocomposite, John Wiley \& Sons, Inc., Hoboken, NJ, USA, 2011, pp. 11.

[25] Anonymous, What is a signal factor, Design of Experiment.

[26] J. Benson, Antimicrobial Copper Kills 97 Percent of Deadly Bacteria, Reduces Infection Rate by 40 Percent, 1st International Conference on Prevention and Infection Control (ICPIC), Geneva, Switzerland, 2011.

[27] R. Rama, G. Padmanabhan, Application of Taguchi methods and ANOVA in optimization of process parameters for metal removal rate in electrochemical machining of $\mathrm{A} 1 / 5 \%$ SiC composites, International Journal of Engineering Research and Applications (IJERA), 2 (2012) 192-197.

[28] A. Ibhadode, I. Dagwa, Development of Asbestos-free Friction Lining Material From Palm Kernel Shell, Journal of the Brazilian Society of Mechanical Sciences and Engineering, 30 (2008) 166-173.

[29] A. Zaharudin, R. Talib, M. Berhan, S. Budin, M. Aziurah, Taguchi Method for Optimizing The Manufacturing Parameters of Friction Materials, International Journal of Mechanical and Materials Engineering, 8 (2012) 83-88. 